
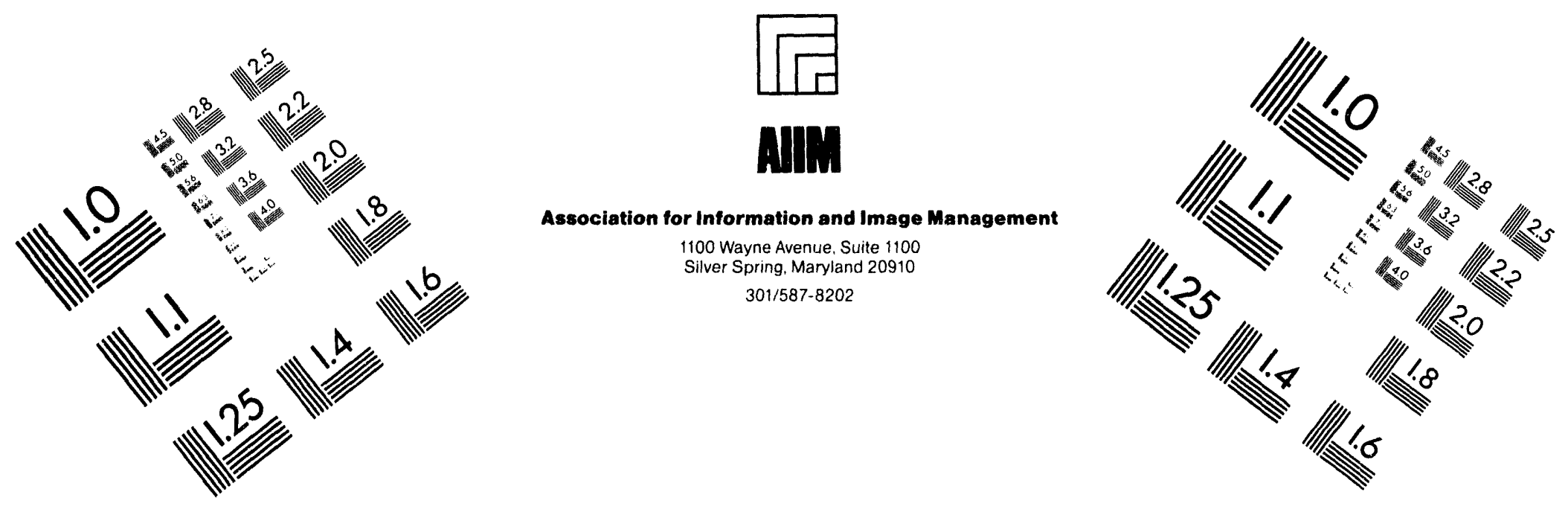

Centimeter

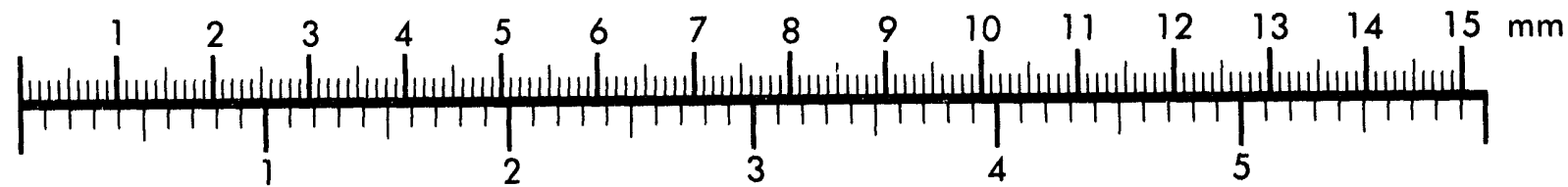

Inches
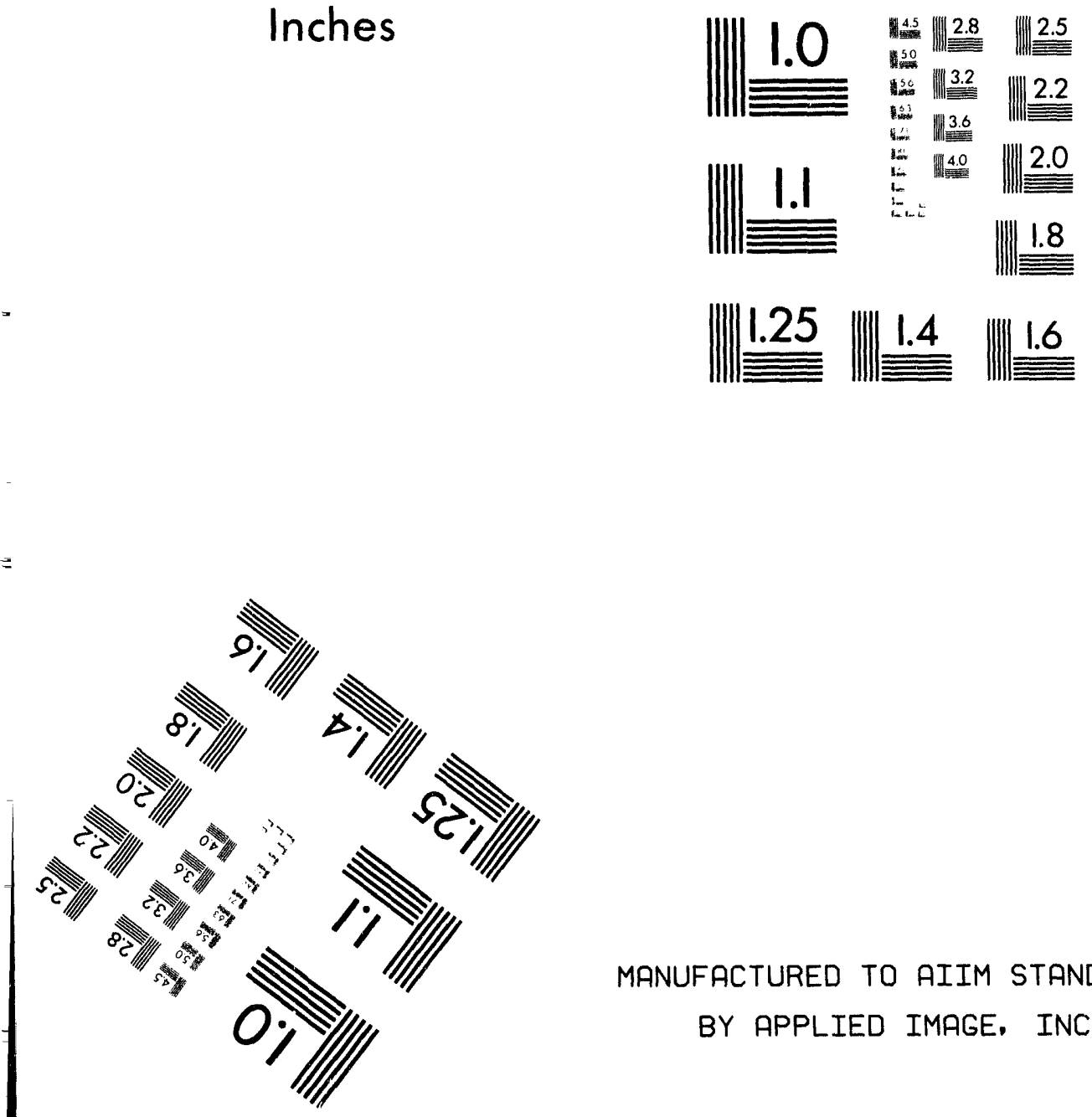

MANUFACTURED TO AIIM STANDARDS

BY APPLIED IMAGE, INC.

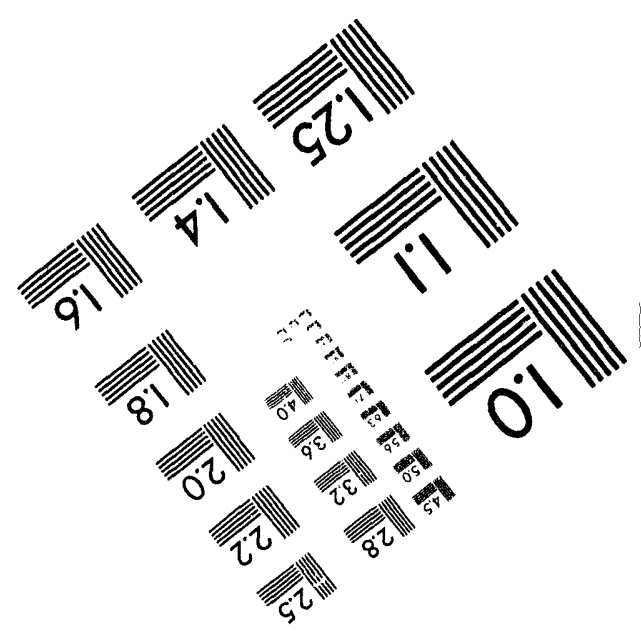



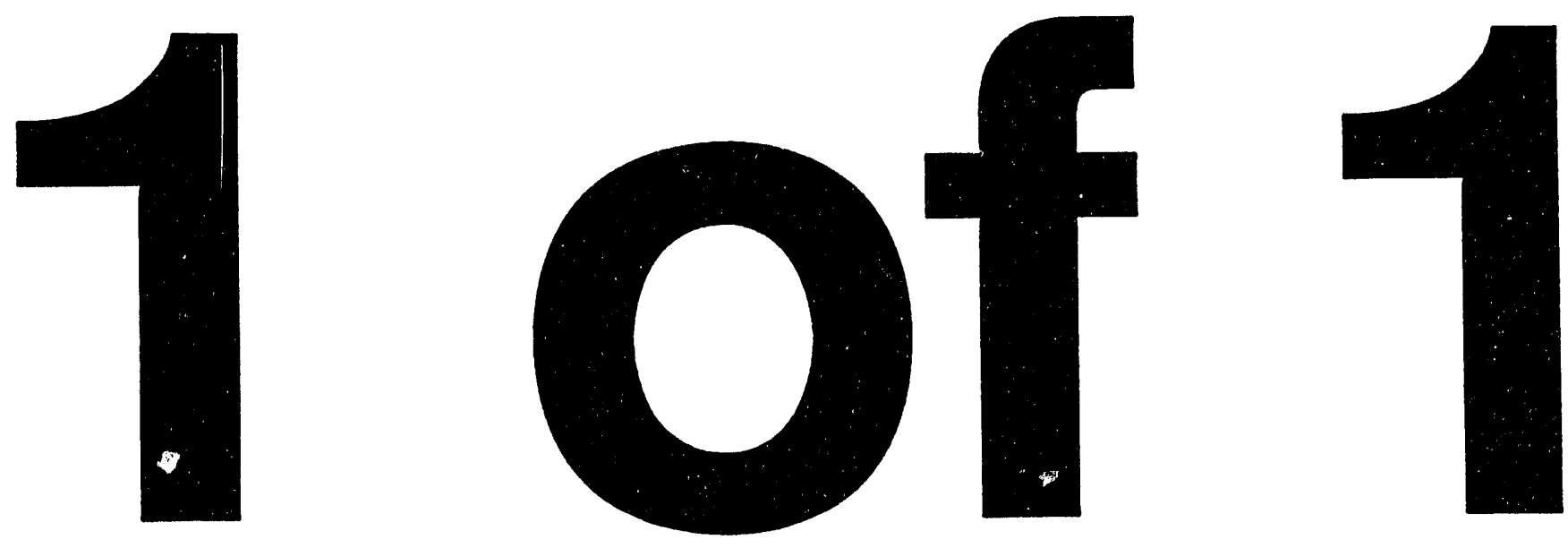


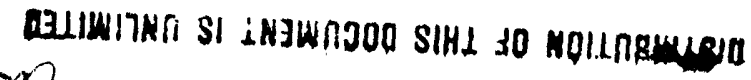

top

Wys

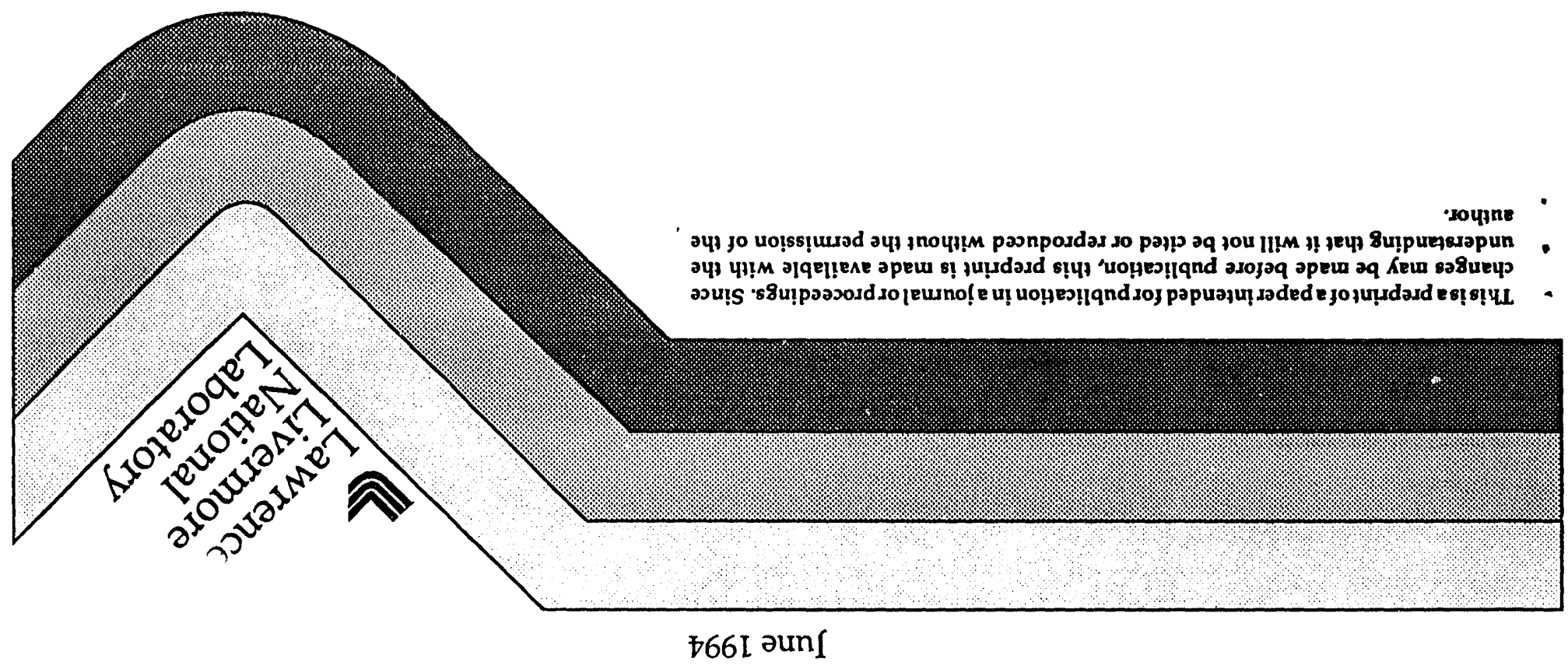

$766 I^{\prime} \varepsilon Z-6 L$ ounl

$\forall T^{\prime}$ 'sueวIIO MON

8ụ๋ว

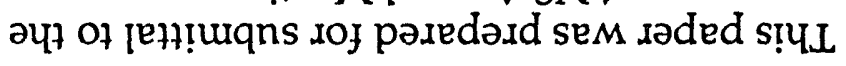

sure!II!M $M$ pue aumoyuax $\cdot \mathrm{g} \cdot 1$

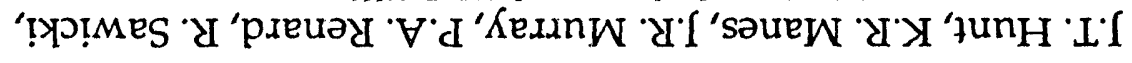

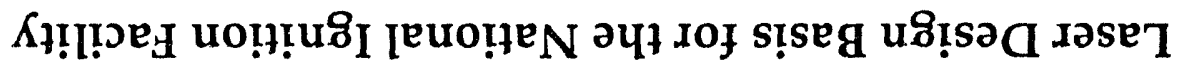

LNIYUAGUd

66ยLLI-כF-TУDก

as. Orgatib-juOJ 
This document was prepared as an account of work sponsored by an agency of the United States Government. Neither the United States Goverament nor the University of California nor any of their employees, makes any warranty, express or Implied, or assumes any legal liability or responsibility for the accuracy, completeness, or usefulness of any information, apparatus, produch, or process disclosed, or represents that its use would not infringe privately owned rights. Reference herein to any specific commercial products, process, or service by trade mame, trademark, manufacturer, or otherwise, does wot necessarily constitute or imply its endorsement, recommendation, or favoring by the United States Government or the University of California. The views and opinions of authors expressed herein do not mecessarily state or reflect those of the United States Governinent or the University of Californim, and stall not be used for advertising or product endorsement purposes. 


\title{
LASER DESIGN BASIS FOR THE NATIONAL IGNITION FACILITY
}

\author{
J.T. Hunt, K.R. Manes, J.R. Murray, P.A. Renard, R. Sawicki, \\ J.B. Trenholme and W. Williams \\ Lawrence Livermore National Laboratory \\ P.O. Box 808 \\ Livermore, CA $94551-9900$
}

\section{ABSTRACT}

Controlled nuclear fusion initiated by highly intense laser beams has been the subject of experiment for many years. The National Ignition Facility (NIF) represents the culmination of design efforts to provide a laser facility that will successfully demonstrate fusion ignition in the laboratory. In this so-called inertial confinement approach, energetic driver beams (laser, $\mathrm{X}$ ray, or charged particle) heat the outer surface of a spherical capsule containing deuterium and tritium (DT) fuel. As the capsule surface explosively evaporates, reaction pressure compresses the DT fuel causing the central core of the fuel to reach extreme density and temperature. When the central temperature is high enough, DT fusion reactions occur. The energy released from these reactions further heats the compressed fuel, and fusion burn propagates outward through the colder regions of the capsule much more rapidly than the inertially confined capsule can expand. The resulting fusion reactions yield many times more energy than was absorbed from the driver beams. Figure 1 summarizes the inertial confinement fusion (ICF) process.

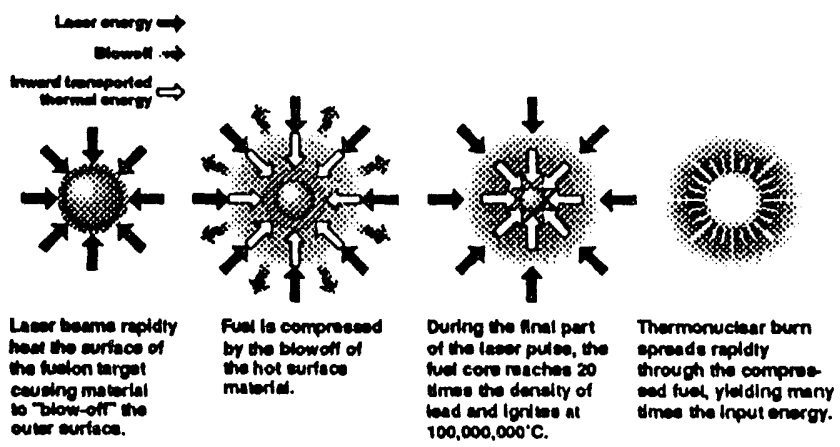

Foure 1. The Inertial Confinement Fueion (ICF) concept.

\section{INTRODUCTION}

Using Nd:glass lasers as the energetic driver, NIF has been designed to address the two basic approaches for coupling drive energy to the target. In the direct-drive approach, laser beams impinge directly on the outer surface of the fusion target capsule. This implies efficient use of the laser energy, but requires a spherically uniform source of laser illumination so that the implosion proceeds in a hydrodynamically stable manner. In the indirect-drive approach, laser beams enter a small metal cylinder called a hohlraum, heating its inner surface to produce $X$ rays. In turn, these thermal $X$ rays strike the DT fusion capsule contained inside the hohlraum, thus indirectly driving the implosion. Illumination uniformity by the laser is less critical for the indirect-drive approach, and the hohlraum can be designed to improve hydrodynamic stability, but indirect-drive targets usually require somewhat more energy from the laser.

\section{REQUIREMENTS}

When designing a laser for inertially confined fusion processes, the wavelength of the drive pulse, its spatial and temporal characteristics, the number of individual laser beams used to generate the required drive energy and power are all dictated by the class of targets expected for the ignition experiment. For example, the indirect-drive NIF ignition target shown in Figure 2 is expected to produce $25 \mathrm{MJ}$ of thermonuclear energy when irradiated by the shaped laser pulse shown in Figure 3. This spatially symmetric, ultraviolet laser pulse has an energy of $1.8 \mathrm{MJ}$ and is shaped to produce a peak power of $500 \mathrm{TW}$. It is expected to produce a hohlraum temperature of $300 \mathrm{eV}$. Such target performance is based on detailed calculations and experimental data obtained from glass lasers and from

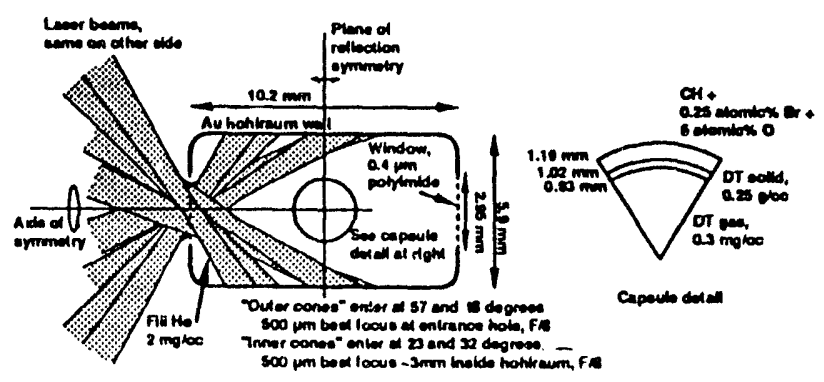

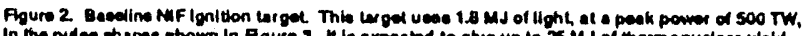




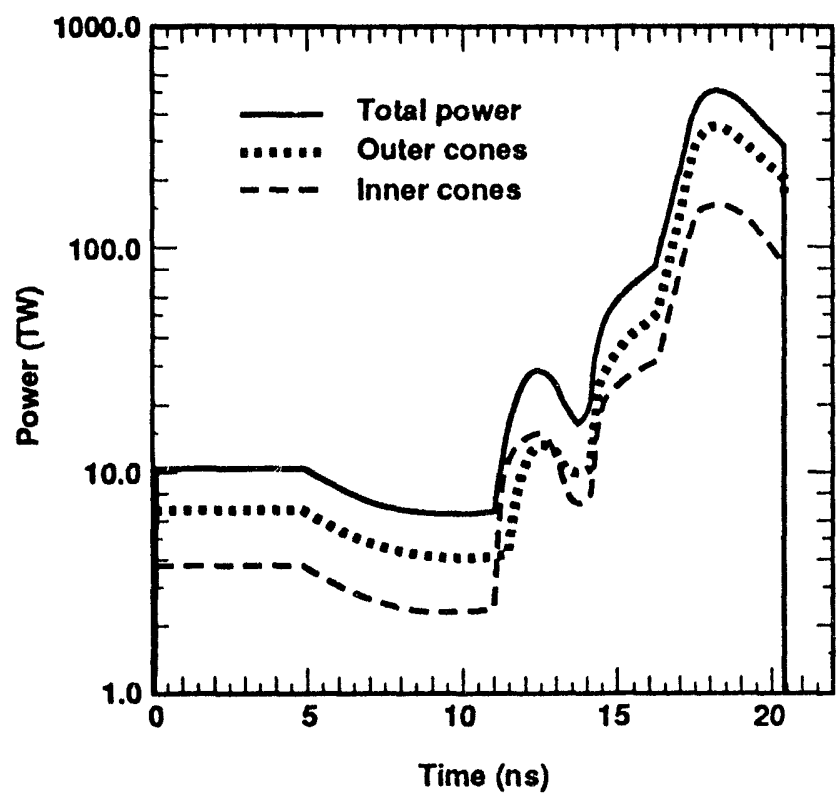

Fgure 3. Pulces on the inner and outer conee have different compord chapes, as

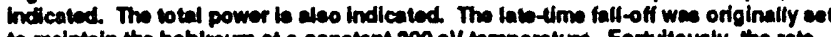
wo maintain the hohiraum at a constant 300 eV comperature. Fortultously, the rate

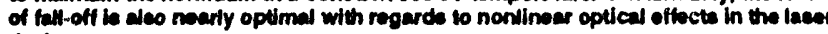
dealgn.

the Halite/Centurion series of underground tests dedicated to ICF physics. ${ }^{1}$ This basic indirect-drive target is a simple, single shell capsule with low atomic number ablater and a central fuel region, surrounded by a cylindrical hohlraum made of high atomic number material. Multiple laser beams enter through holes in the ends of the hohlraum and irradiate the interior wall. In the discussion that follows, we continue to use criteria for the indirec:drive target, since those do not exclude the direct-drive targets.

Multiple laser beams are used to achieve the required power and energy, and to help provide the symmetry that reduces any hydrodynamic instability of the energy coupling and implosion processes. For the indirect-drive target, two-sided irradiation, with each side composed of two cones of beams, provide the necessary symmetry. These cones lie at elevation half-angles of $\sim 27$ degrees and $\sim 53$ degrees with a nominal division in laser energy of $1 / 3$ in the inner cone and $2 / 3$ in the outer cone. Additionally, at least an eight-fold rotation symmetry in the azimuth angle about the hohlraum axis is required to reduce the amplitude of low order spherical harmonic terms in the drive pressure-again, an implosion symmetry requirement.

Multiple wavelengths (up to four) of the laser drive, overlapped at focus, are used to temporally smooth the drive and minimize plasma instabilities caused by interac- tion between laser intensity and density and temperature of plasma produced inside the hohlraum. The beat pattern of such a spread of wavelengths changes the beam profile at focus in times of $\sim 10$ picoseconds. Kinoform phase plates located in the post focusing region of the drive impose spatial smoothing of the beams' 500 micron focal spot.

It is these symmetry and smoothing requirements that determine the minimum number of beams as follows:

number of beams $=(4$ wavelengths $) \times(1$ beam in an inner cone +2 in an outer cone $) \times(8$ fold symmetry $)$ $\times(2$ sides $)=192$

Thus, for indirect-drive targets, NIF should contain at least 192 individual laser beam lines. Pulses from each of these must be delivered on target according to stringent requirements in time and space to avoid power imbalance between beams. This instantaneous power balance sets criteria for mechanical adjustment of pulse arrival times.

Figure 4 summarizes the top level target requirements and how they determine the laser's characteristics.

NIF was not designed in response to one specific target configuration. Rather, it was designed to address the requirements of a broad class of targets. This was done by

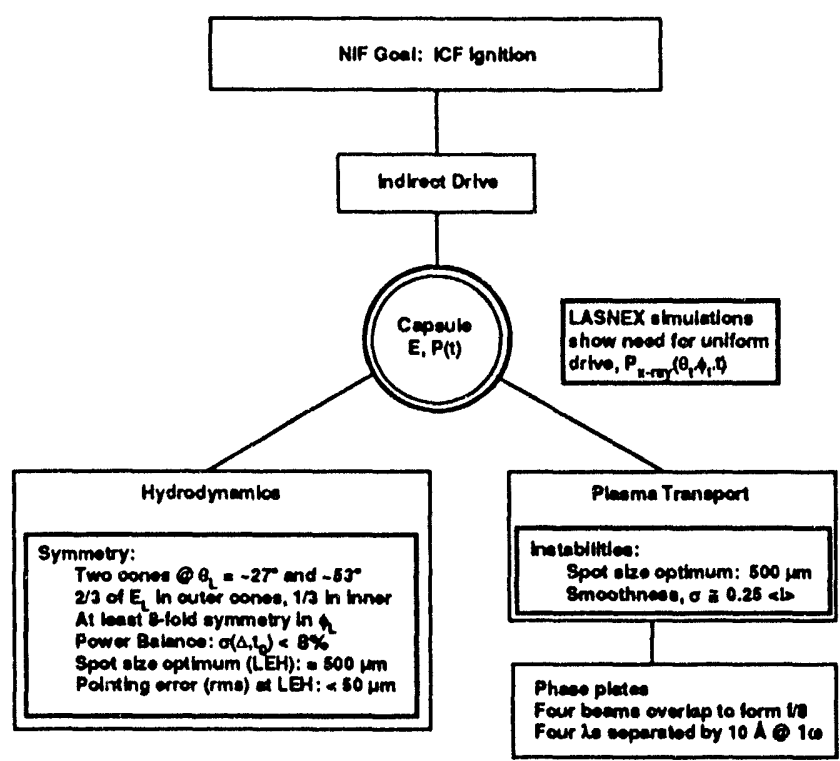

Figure 4. Ignition requirement for indirect-drive targets.

deriving a formula that estimates the safety factor or target margin for any NIF indirect-drive ignition target. This figure of merit represents the available energy beyond the minimum required for ignition of a particular target, or the safety factor in laser intensity above which laser-plasma instabilities occur in that target. This figure of merit is 
parameterized by a scaled capsule radius, $R$, and hohlraum temperature, T. For each point in R-T space there is a specific temporal shape for the incident $3 \omega$ laser drive pulse and, therefore, a unique laser design. This information is enough to construct the contour plot in Figure 5 showing the expected target margin for ignition as a function of peak ultraviolet power and total ultraviolet energy in the laser drive pulse.

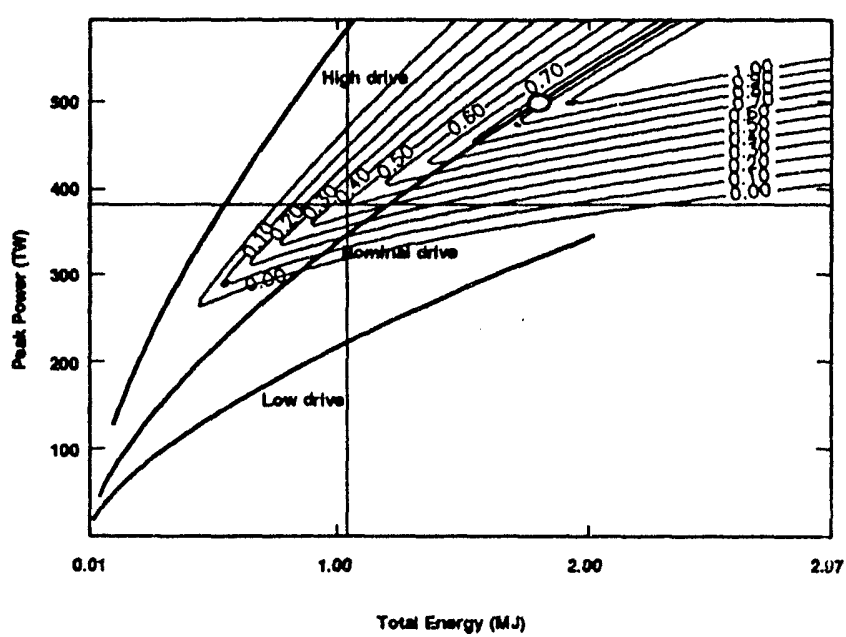

Figure 5. The target margin or anfety factor is reprecented by a contour. The total UV energy and peak power incidert on the lacer entrance hole to the target are provided axes values. Each point on the plane corresponde to $a$ unique proveral putce. The beceline design le marked by a white dot

\section{CONSTRAINTS}

It emerges from the target design considerations just discussed that the NIF laser must meet the following top level requirements:

Energy: 1.8 megajoules

Peak power: 500 terawatts

Pulse duration: 20 nanoseconds

Target irradiating

Wavelength: 0.351 micrometers

Focal spot: 500 micrometers diameter and smooth

Pulse shape: complex with a 50 to 1 contrast ratio

Designing a solid state laser to meet these requirements is well within current technological grasp. Flashlamp pumped Nd:glass lasers that have been used to irradiate ICF targets since the early 1970 s have been successfully scaled from a few tens of joules to an energy of 120 kilojoules in a few nanoseconds. ${ }^{2}$ With this demonstrated ability to scale in energy, and because of the maturity of the Nd:glass laser technology, it is appropriate that this type of laser be used for the megajoule class NIF laser system. The target irradiating wavelength of 0.351 micrometer is generated from the 1.053 micrometer beam produced by Nd:glass lasers with frequency triplers ${ }^{3,4}$ placed upstream of the lasers' final focusing lens.

There is a Laser Design Basis Report (LDB) describing cost and performance foundations for the NIF laser system. ${ }^{5}$ NIF is a multipass design with four passes through the large final amplifier. Multipass systems dispense with many intermediate laser amplifier stages, so they are significantly less expensive than single-pass designs such as used in previous fusion lasers. The LPB also describes a complex computer-based optimization procedure that manipulates kcy design parameters to maximize a laser's output energy-per-dollar based on some baseline target and particular temporal pulse shape. The optimization procedure relies on engineering cost data, component performance test data, and extensive computer simulations of laser performance. Two of the most important facts reported by the LDB are:

1) the optics element with the lowest damage threshold is the frequency tripler

2) the most cost effective laser design uses the fewest large aperture beams.

As applied to NIF, these constraints provide a simple characterization in terms of total aperture (sum of all beamlines) of the laser system.

The minimum allowed total aperture is determined by the ultraviolet beam fluence at which the frequency tripler experiences damage for the pulse shape shown in Figure 3; this threshold is $\sim 14 \mathrm{~J} / \mathrm{cm}^{2}$. Applying a $30 \%$ safety margin, the NIF laser is designed to operate at a mean fluence of $\sim 9.5 \mathrm{~J} / \mathrm{cm}^{2}$ at the triple: With an additional aperture filling factor of $80 \%$ for any individual beamline (as specified in the LDB), and a presumed $90 \%$ transport efficiency in post tripler optics, the minimum total aperture for producing a $1.8 \mathrm{MJ}$ ultraviolet target irradiance pulse is $\sim 26$ square meters.

The maximum area of any single laser beam in the multi-beam NIF is limited by a threshold for stimulated Raman scattering in the frequency tripler, the need to control transverse parasitics in the amplifier optics, and the ability to grow and finish large aperture, defect-free, crystal components. Experimental data and calculation suggest that these phenomena limit any aperture for a single beam to about $1600 \mathrm{~cm}^{2}$. As pointed out by the LDB, the most cost effective laser system will have this aperture size.

Combining the maximum allowed single aperture size with the minimum total aperture produces a count of 162 laser beams, each with clear aperture of $1600 \mathrm{~cm}^{2}$, to 
produce the $1.8 \mathrm{MJ}$ ultraviolet pulse-provided that power and energetics were the only specifications for the NIF lasers. The symmetry and beam smoothing requirements discussed earlier demand at least 192 beams. Because prudent enginecring of any large systems will include a design margin, the choice of the NIF laser design with 192 beams with a clear aperture of $40 \mathrm{~cm}$ provides a reasonable margin of $\sim 30$ beams, or $18 \%$.

Of singular concern to NIF is the ability to deliver on target a temporally shaped pulse as shown in Figure 3. Gain saturation in the laser amplifier and intensity dependent frequency tripling will cause an injected pulse to change shape. By traversing the laser in reverse order, from target to injection, it is possible to predict an appropriate input temporal shape. The intensity dependent tripling efficiency shown in Figure 6 is typical of the design expected for NIF. Though it has an $85 \%$ peak power conversion, the overall energy conversion for a pulse like that in Figure 3 is about 60\%. Figure 7 summarizes this energy flow through the laser, and shows that the one micron NIF laser must deliver an $\sim 650$ TW peak power, $\sim 3.4 \mathrm{MJ}$ total energy pulse to the tripler so that the target sees a $500 \mathrm{TW} / 1.8 \mathrm{MJ}$ one third micron pulse.

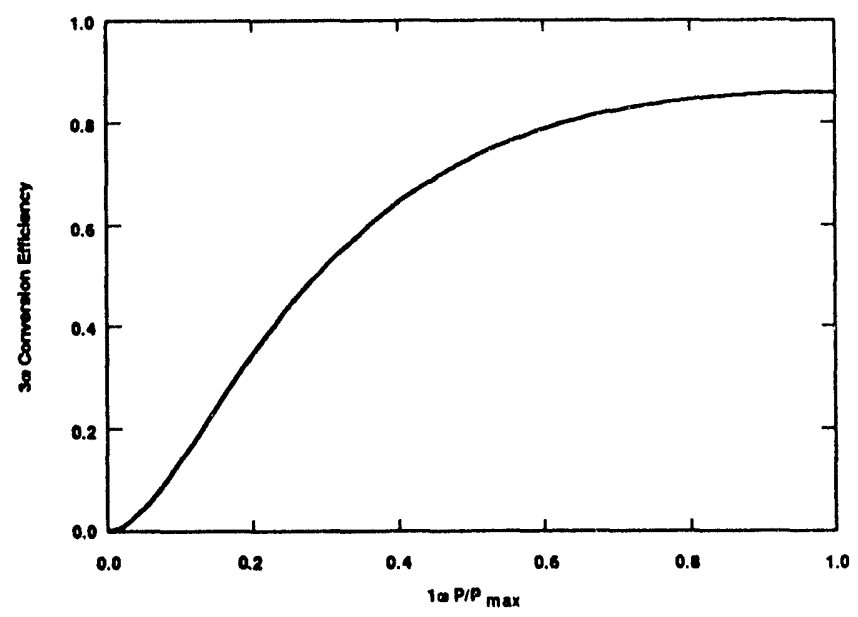

Fgure 6. 3co convercion efficiency curves used in the pulee thaping analyeis.

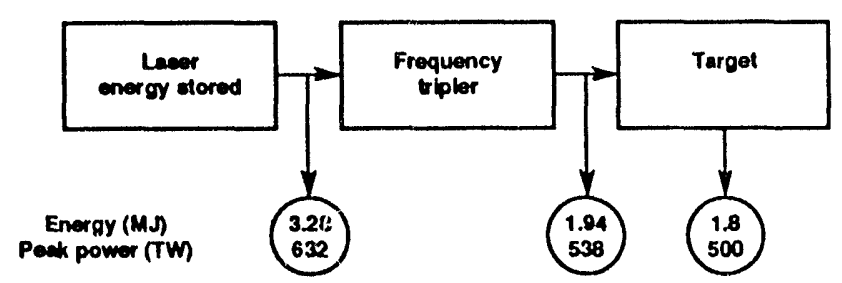

Figure 7. The relationahip betwoen the 36 pulee and the 1 co pulee required to gonerate it. A tranemiscion efficiency of s0\% from the tripler to the target was used in this model.

\section{SUMMARY}

The NIF laser design is one among a family of lasers that could meet the $1.8 \mathrm{MJ} / 500 \mathrm{TW}$ ignition requirement. Cost optimization applied to this family for a baseline target and particular pulse shape produces a design optimal for this design point, but also encompasses a wide range of other targe//pulse shape configurations. Figure 8 shows the performance of a 192 count, $40-\mathrm{cm} \times 40-\mathrm{cm}$ aperture system for pewer pulses scaled to the shape shown in Figure 3. An overall performance margin of $\sim 20 \%$ separates baseline operation from a damage-limited (to any component), redline performance for the 192-beam case.

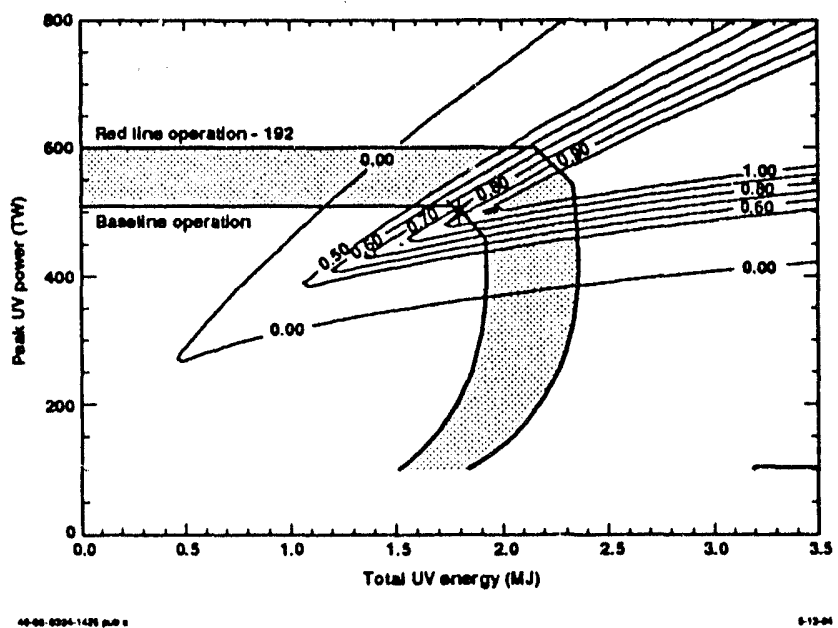

Figure a. Acremible Puv, Eur apace. The 19-beamlet came reaches "rod line" or damage linailed performance at the lop of the gray band.

\section{ACKNOWLEDGMENTS}

This work was performed under the auspices of the U.S. Department of Energy by Lawrence Livermore National Laboratory under contract no. W-7405-ENG-48.

\section{REFERENCES}

1. John D. Lindl, Robert L. McCrory, and E. Michael Campbell, "Progress toward ignition and burn propagation in inertial confinement fusion," PHYSICS TODAY, 45, 9, pp. 32-41 (1992).

2. C. Bibcau, D. R. Speck, R. B. Ehrlich, C.W. Laumann, D. T. Kyrazis, M. A. Henesian, J. K. Lawson, M. D. Peng, P. J. Wegner, and T. L. Weiland, "Power, energy, and temporal performance of the Nova laser facility with recent improvements to the amplifier system," APPLIED OPTICS, 31, pp. 5799 -5809 (1992).

3. R. S. Craxton, "High efficiency frequency tripling schemes for high power Nd:glass lasers," IEEE J. QUANT. ELECT., QE-17, pp. 1771-1782 (1981). 
4. P. J. Wegner, M. A. Henesian, D. R. Speck, C. Bibeau, R. B. Ehrlich, C. W. Laumann, J. K. Lawson, and T. L. Weiland, "Harmonic conversion of large-aperture $1.05 \mu \mathrm{m}$ laser beams for inertial confinement fusion research," APPL OPT, 31, pp. 6414-6426 (1992).

5. "National Ignition Facility, Laser Design and Cost Basis," Univ. of California, Lawrence Livermore National Laboratory, UCRL-UR-117-387, August 1993. 

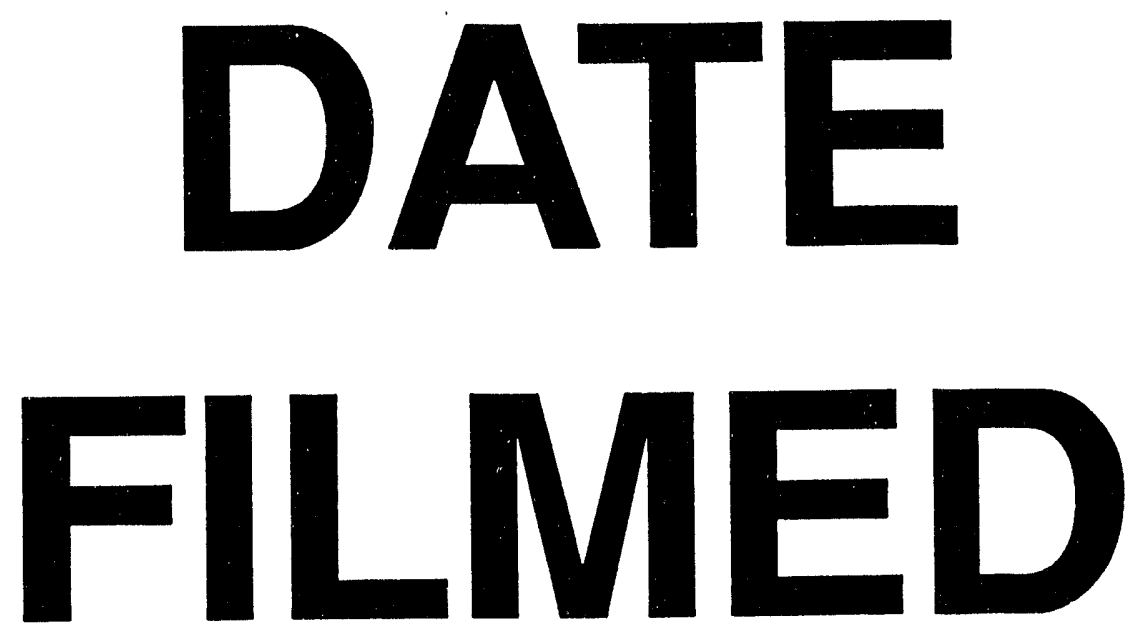

$9 / 29 / 94$
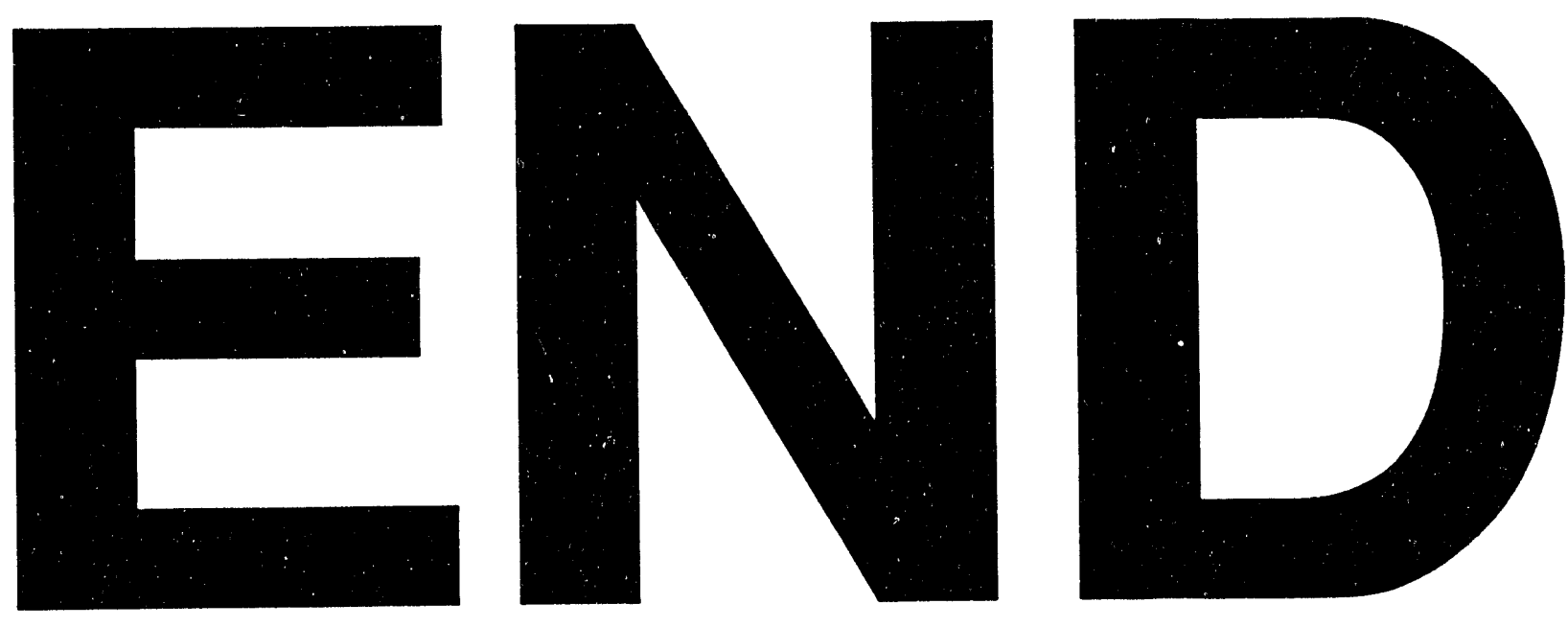
